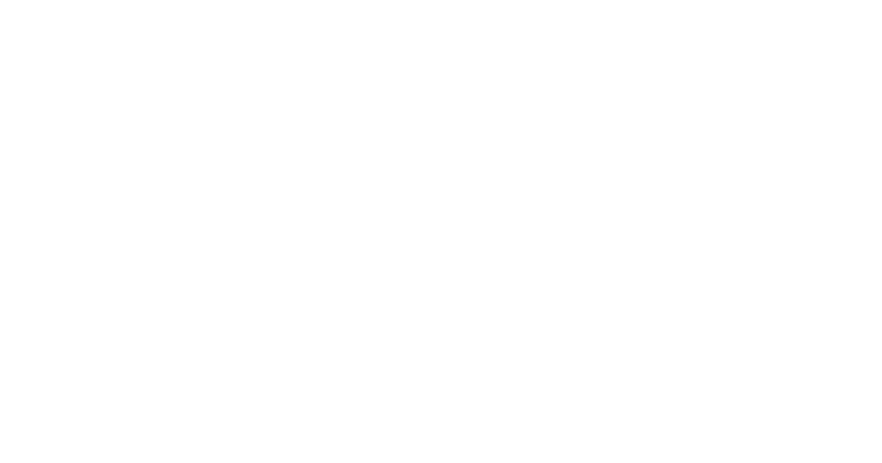

\title{
La problemática fiscal actual
}

- n el pensamiento económico dominante, la - política económica del país tiene por objetivo mejorar el nivel de crecimiento, entendiendo por esto el mero aumento de la producción de bienes y servicios. Sin embargo, para otras corrientes, entre las que se incluye la promovida por el Programa de la Naciones Unidas para el Desarrollo (PNUD), el objetivo último de la política pública en general y de la económica en particular debería ser lograr el desarrollo económico, social y cultural de la ciudadanía, de tal manera que todas las personas sean capaces de lograr lo que se conoce como desarrollo humano.

Dentro de la variedad de acciones políticas con que cuentan los estados para lograr el objetivo de desarrollo humano, la política fiscal posee un lugar relevante en tanto pretende lograr que el Estado se apropie de una parte del producto social para atender las necesidades vitales de la colectividad y asegurar un nivel de bienestar mínimo y adecuado para todos. La apropiación del producto social se hace desde las clases que acumulan mayor ingreso y riqueza para distribuirlas hacia las que acumulan menos, con lo cual se tiende a lograr el objetivo de universalizar el bienestar y se promueve una mayor equidad entre la población. 
La realidad de nuestro país no suele concordar con los ideales de desarrollo o con el deber ser de las políticas. Así, El Salvador es un país caracterizado, entre otras cosas, por el alto grado de inequidad que existe a todo nivel. No se trata sólo de desigualdad o inequidad de ingresos, sino también, en la posesión de activo, en el acceso a bienes y servicios básicos y, por supuesto, en el pago de impuestos.

Es de esperar que en un país en el que el Estado procura la equidad se apropie más de aquellos que poseen más ingreso o riqueza y menos de aquellos que poseen menos ingreso y riqueza. Uno de los impuestos más conocidos es el impuesto a la renta. Para simplificar, diremos que el valor de la producción remunera a los factores productivos, que son el trabajo y el capital, con lo cual se puede decir que el Producto Interno Bruto (PIB) se reparte entre la remuneración al capital y al trabajo. Del total de bienes y servicios que produce el país en un año resulta, de acuerdo a los datos oficiales de las cuentas nacionales elaboradas por el Banco Central de Reserva, que la renta del factor capital corresponde con cerca de dos tercios del total, mientras que la renta de las personas o salarios contribuye con un tercio. El factor capital, al final, pertenece a personas que han arriesgado su dinero iniciando una empresa con el objeto de ganar utilidades o renta. Se puede decir entonces que la renta de las empresas o del capital pertenece a los grupos con poder económi$\mathrm{co}$, mientras que la renta de trabajo pertenece a la clase trabajadora. Un impuesto a la renta neutral en términos de equidad debería permitir que esta proporción se mantenga en la recaudación. De ser así, el impuesto a la renta no contribuye a mejorar la equidad pero tampoco contribuye a desmejorarla. Si bien esta situación no corresponde con el objetivo de mejorar y equilibrar el bienestar de la colectividad a través de la apropiación y distribución del producto social, al menos no profundiza la desigualdad de ingresos y riqueza que la genera.

En El Salvador la recaudación del impuesto a la renta es contraria a la equidad; resulta que la recaudación por renta de personas, que proviene principalmente del salario, es menor que la recaudación por impuesto a la renta de empresas. $O$, dicho de otra manera, las empresas ganan mucho más y pagan menos impuestos que los asalariados. La realidad es que el impuesto a la renta es pagado en su mayor parte por los trabajadores asalariados y mucho menos por la renta de empresas. Esto se explica no sólo por la propensión a la elusión y evasión del sector empresarial formal, sino también por la propensión del Estado salvadoreño a otorgar beneficios a la clase dominante del país presionados por una élite empresarial influyente y que se opone continuamente a toda política que fortalezca la tributación directa, ya sea de renta o patrimonio. Como 
ejemplos relevantes de lo anterior se encuentran todas las empresas ubicadas en las zonas francas del país, las cuales se encuentran exentas del pago de varios tipos de impuestos, como son los siguientes: $100 \%$ de exención para el total de materias primas, maquinaria y equipo importado, $100 \%$ de renta e impuestos y tasas municipales por 20 años, 100\% de repatriación de ganancias y activos e IVA por diez años prorrogables. Sin lugar a dudas, se puede afirmar que lo único que aportan las empresas que se encuentran en las zonas francas son los salarios, los cuales se caracterizan por ser más bien bajos y, en caso de ser altos, están sujetos al pago de impuesto a la renta. En la actualidad ha surgido un nuevo sector importante: el turismo, para el cual se está implantando una estrategia muy similar, en tanto exime de impuestos a las grandes inversiones.

Así como ha existido una clara determinación del gobierno de no captar ingresos que provengan de las renta de las clases altas de la sociedad, también ha existido una clara preferencia por lograr apropiación del producto socialmente creado a través de la tributación indirecta. Así, en la actualidad el peso de la estructura tributaria está cargado hacia el Impuesto al Valor Agregado (IVA). A finales de los años ochenta, la estructura descansaba mayoritariamente en los impuestos al comercio exterior y en el impuesto al timbre (sustituido por el IVA a inicios del programa de ajuste estructural implementado por la administración Cristiani). Ya en 1995 los impuestos a la exportación dejaron de generar ingresos al gobierno, en la actualidad la tributación indirecta (IVA, impuestos selectivos al consumo como al tabaco, gasolina y alcohol) representa más del $65 \%$ del total de recaudación y el IVA representa el 52.6\% del total de recaudación. Aunque hubo una oposición a este impuesto por parte de la sociedad civil, sobre todo debido a su sesgo claramente regresivo, ello contrastó con la anuencia de la élite empresarial con el impuesto al valor agregado. Al mismo tiempo, esta élite se opuso tajantemente a cualquier reforma que fortaleciera la tributación directa.

La actual estructura tributaria es menos equitativa que la que se tenía en la época agroexportadora, pues en esta época los sectores con mayor capacidad de acumulación (café, algodón y azúcar) contribuían con impuestos a la exportación y constituían una importante fuente de ingresos para el gobierno; mientras que en la actualidad los sectores con mayor capacidad de acumulación contribuyen poco o nada, ya sea por práctica sistemática de la elusión (permitida por las leyes) e incluso evasión, y por la política de exención de impuestos a sectores específicos como el turismo o por las zonas francas.

La inequidad de la política tributaria y con ello la ineficacia del estado en apoyar el desarrollo de la colectividad se expresa de forma inobjetable 
con los datos de la Carga Tributaria Diferenciada (CTD) calculada en un estudio del Banco Interamericano de Desarrollo (BID). Según este estudio, el quintil más pobre contribuye con un $210 \%$ más que el promedio, mientras el más rico hace lo propio con un $20 \%$ menos que el promedio. De cada 100 dólares que paga en impuestos un ciudadano promedio, los más ricos del país contribuyen con 80 dólares, mientras que los más pobres pagan 210 dólares

Si se hicieran esfuerzos por eliminar tanto la elusión como la evasión y el exceso de incentivos fiscales para quienes no los necesitan, posiblemente la carga tributaria podría aumentar al menos 5.1 puntos porcentuales, al mismo tiempo que se abonaría a una mayor equidad. Nuestra política tributaria es proclive a profundizar los niveles de concentración. Así, estudios de la Comisión Económica para América Latina (CEPAL) confirman que la elasticidad en el ingreso de los impuestos es menor que uno. Esto significa que cuando aumenta el ingreso de los contribuyentes el pago de impuestos no aumenta en igual proporción, sino que aumenta menos. Es decir que, a mayor ingreso, menor proporción en el pago de impuestos. Esto, nuevamente, es contrario a la equidad, pues los que tienen mayores ingresos, al ganar más, pagan menos impuestos; lo opuesto sucede con los que tienen menos y pierden ingresos: resulta que lo que dejan de pagar en impuestos no es tanto.

Sin profundizar sobre la otra cara de la política fiscal y la política de gastos, se puede al menos poner en duda que el objetivo del gobierno sea beneficiar a las clases con menores ingresos. Lo que las evidencias de las acciones de política tributaria y sus resultados indican es la preferencia por las clases altas, profundizando así la inequidad entre ciudadanos.

Estos resultados llevan a una frustración sobre la incapacidad manifiesta de los gobiernos de los últimos quinquenios para procurar el bienestar de la sociedad, a tal punto que incluso cuestiona el régimen democrático y la distribución de poderes entre el ejecutivo, legislativo y judicial. La incapacidad del poder ejecutivo en procurar el bienestar y desarrollo humano de todos se manifiesta en su incapacidad para lograr crear cuerpos legales que apoyen la equidad. Por su parte, tampoco el poder judicial logra garantizar la vigencia de la Constitución, la cual, en su artículo primero, literalmente reza: "El Salvador reconoce a la persona humana como el origen y el fin de la actividad del Estado, que está organizado para la consecución de la justicia, de la seguridad jurídica y del bien común. En consecuencia, es obligación del Estado asegurar a los habitantes de la República, el goce de la libertad, la salud, la cultura, el bienestar económico y la justicia social.". 